Originalveröffentlichung in: Heidelberger Jahrbücher, Neue Folge, Bd.1, Heidelberg 1957,

S.111-132

\title{
DIE HEIDELBERGER KARMELITENKIRCHE ST. JACOBUS MAJOR ${ }^{1}$ )
}

\author{
Von Peter Anselm Riedl
}

Keine Ruine, kein Gedenkstein erinnert heute mehr an die Heidelberger Karmelitenkirche, jenen Bau, der als kurfürstliche Begräbnisstätte im achtzehnten Jahrhundert alle anderen Heidelberger Gotteshäuser an Bedeutung überragte. Und von der ehedem so großzügigen Anlage des Karmelitenklosters zeugen nur verstümmelte und profanierte Reste am terrassierten Hang östlich des Friesenbergwegs.

Die Geschichtsforschung hat freilich schon längst die Wichtigkeit jener vergangenen Baudenkmäler erkannt und gewürdigt. Friedrich Walter und Herbert Derwein haben deutlich gemacht, wie sehr es gerade dem Karmelitenkloster und seiner Kirche zu danken ist, daß sich der kurfürstliche Hof nach der Residenzverlegung Heidelberg nicht allzu sehr entfremdete ${ }^{2}$ ). DER weIn hat, indem er erstmals die HeRTwigsche "Chronik des Barfüßer Karmelitenklosters zu Heidelberg" ${ }^{3}$ ) als Quelle heranzog, wichtige Erkenntnisse zutage gefördert. Früher noch als die genannten Historiker aber hatte sich schon Adolf von OechelHaeuser der Erforschung der Karmelitenkirche angenommen ${ }^{4}$ ); die Abbildung des Baus im "Thesaurus Palatinus" (Abb.1) schien ihm für Adam Breunig als Architekten zu sprechen, also den Mann, der Hei-

1) Die vorliegende Untersuchung gehörte als Exkurs zu der 1955 eingereichten Heidelberger Dissertation des Verfassers: „Die Heidelberger Jesuitenkirche und die Hallenkirchen des 17. und 18. Jahrhunderts in Süddeutschland“. Inzwischen ist die Dissertation mit Ausnahme eben dieses Exkurses in der Reihe der "Heidelberger Kunstgeschichtlichen Abhandlungen" (Neue Folge 3, Heidelberg 1956; hier zitiert als "RIEDL, Heidelberger Jesuitenkirche“) erschienen.

2) Friedrich Walter: Mannheimer Geschichtsblätter 16 (1915) 119. - Herbert Derwein: Das Karmelitenkloster in Heidelberg. Wochenbeilage des Heidelberger Tageblatts vom 13. 2. 1932. - Herrn Stadtarchivar Dr. Herbert Derwern, Heidelberg, habe ich aufrichtig für manchen wichtigen Hinweis zu danken. - FrIEDRICH WALTER: Eine zweite Wittelsbacher Begräbnisstätte in Heidelberg. Heidelberger Fremdenblatt, 2. Aprilheft 1952.

${ }^{3}$ ) Chronik des Barfüßer Karmelitenklosters zu Heidelberg. Ein Beytrag zur Pfälzischen Kirchengeschichte. - Von anderer Hand hinzugefügt: „Der Verfasser ist der Carmeliten Pater Gregor Hertwig, der, 73 Jahre alt, am 20. Februar 1815 in Heidelberg starb. Die Chronik ist 1803-1806, der Schluß 1809 geschrieben “. Universitätsbibliothek Heidelberg, HS. 1199. - Hertwig fußt nach eigenen Angaben (Vorwort) vornehmlich auf der „Relatio historica initii ac successus fundationis Conventus Heidelbergensis F. F. Carmelitarum discalceatorum; inchoata anno 1700“. - Ich zitiere die Hertwigsche Chronik als "HeRTwIG“.

$\left.{ }^{4}\right)$ Adolf von Oechelhaeuser: Die Kunstdenkmäler des Großherzogtums Baden, Bd. 8, Abt. 2, Tübingen 1913, S. 116. 
delberg die Jesuitenkirche, die Alte Universität und das Palais Morass - um nur einige Werke zu nennen - geschenkt hat. KARL LOHMEYER übernahm Oechelhaeusers Vermutung ${ }^{5}$ ). Die von Oechelhaeuser (allerdings mit dem Hinweis auf mögliche Unzuverlässigkeit) angeführte Entstehungszeit der Kirche, 1701, schien gut mit den sonstigen Kenntnissen über Breunig vereinbar.

Oechelhaeuser hat offenbar den mehrfach überlieferten Tatbestand der im Jahre 1701 erfolgten Ansiedlung von Karmelitenmönchen mit der Erbauung der Kirche in direkten Zusammenhang gebracht. Daher müssen seine Ausführungen über die Geschichte der alten Jakobskirche, die - wie er richtig darstellt - die Vorgängerin der Karmelitenkirche St. Jakob war, mit der Erläuterung schließen, jene alte Jakobskirche sei unter dem Kurfürsten Philipp Wilhelm erneuert, im Erbfolgekrieg indessen wieder vernichtet worden. WALTER folgt dieser Auffassung, wenn er schreibt: „Das Kloster der Karmeliten Barfüßer in Heidelberg wurde 1701 auf dem verödeten Platz der von den Franzosen zerstörten Jacobskirche errichtet ${ }^{\text {" }}$ ). OECHELHAEusERs und WaLters Auslegung blieb meines Wissen bis heute unwidersprochen.

In Anbetracht der kunstgeschichtlichen Bedeutung der Karmelitenkirche und der augenscheinlichen Lückenhaftigkeit der bisherigen Forschungsergebnisse schien es angezeigt, der Geschichte des Baus einmal nachzuspüren. Das erwies sich als so lohnend, daß ich es wagen darf, eine kleine Monographie vorzulegen.

\section{Geschichte der Heidelberger Karmelitenkirche}

Johann Peter Kayser berichtet in seinem „Historischen Schau-Platz“ 1733: „Das Carmeliter-Closter stehet vor dem obern Thor, ist reich, schön und prächtig, sonderlich die Kirche, wobey ein schöner Garten, so neulich erweitert worden. Schon ums Jahr 1466 wird dieses St. Jacobs als eines Cistercienser-Closters gedacht, so allhier in der Vorstadt gestanden, welches aber durch den Krieg und die Länge der Zeit scheinet verfallen zu seyn. Nachdem aber Churfürst Philipp Wilhelm, als der erste aus dem Durchläuchtigen Hauss Neuburg zur Regierung kame, fieng er im Jahre 1685 die St. Jacobskirche für die Catholische Religion an zu bauen, und ließe ihnen, biß gemeldte Kirche fertig seyn würde, die Guarnisons-Kirche einräumen. Ließ auch das Decanat darbey aufführen. Woraus hernacher dieses reiche Carmeliter-Closter gestifftet worden. Allhier ruhet der Durchleuchtigste Fürst Joseph Carl Emanuel Augustus, Pfaltzgraf bey Rhein ı. Erb-Printz zu Sultzbach, samt seiner Gemahlin Elisabetha Augusta“ 7). Mit diesem Bericht stimmt im wesentlichen der im "Thesaurus Palatinus" überein; da heißt es unter anderem: „... hat der Churfürst Philipp Wilhelm, Diese Kirche von grund aus, erbauet, und ihr den Nahmen S. Jacobi gelassen, dann ob gleich dermahlen an selbigen ohrt weiter nichts als ein Lehrer Platz zu sehen gewesen, so ist doch annoch in Anno 1476 eine Kirche daselbst zu S. Jacob genannt, nebst einem Cistercienser Closter gestanden. ... Man siehet gleich am Frontispicio dieser Kirche, über dem Eingang Daß Pfaltz Neuburgsche Wappen in Stein gehauen,

5) KarL Lohmeyer: Vom Wiederaufbau des zerstörten Heidelbergs. In: Heidelberg, Deutsche Städte, Stuttgart o. J., S. 22.

6) Walter, a.a.O. (1915), vgl. Anm. 2.

7) Johann Peter Kayser: Historischer Schau-Platz der Alten berühmten Stadt Heidelberg, Frankfurt am Main 1733, S. 90. 
so zwey gegen einander stehende Löwen mit ihren Vortern Pratzen halten, worunter nachfolgende worte $\mathrm{zu}$ lesen:

\author{
Deo. opt. Max: \\ ob auctam patriam
}

Catholico S. R. E. Ritu palatino Neob. Dom. S. R. J. Electoratu Stirpem.

S. E. Solonixam multiplici prole prosapiam Caesar Regum Affinitate Hanc S. Jacobi Ap. AEdem gardus posuit. Philippus Wilhelmus S. R. J. Archithes. Anno MDCLXXXIIX“ ${ }^{8}$ ).

Der Karmeliten-Chronist Pater Hertwig, dessen offenbar auf sehr verläßlichen Quellen fußende Aufzeichnungen uns im folgenden noch oft dienen sollen, läßt sich in ganz ähnlichem Sinne aus: „Der öde Platz, wo vormals die St. Jacobskirche stand, ward zu der neu aufzuführenden Kirche bestimmt ... Als die neue Kirche, die neunzig tausend Gulden kostete, fertig und zum Gottesdienste eingerichtet war, bestimmte sie der Kurfürst zur katholischen Pfarrkirche. ... “ $\left.{ }^{9}\right)$.

Ubereinstimmend ist in den drei zitierten Textstellen von der mittelalterlichen Jakobskirche die Rede; es wird jedesmal darauf hingewiesen, daß sie im Laufe der Zeit verfallen und dort, wo sie einst stand, ein öder Platz zurückgeblieben sei. Inwieweit diese Angabe den Tatsachen entspricht, ist nicht auszumachen. Jedenfalls ist auf Merians großem Heidelberg-Stich (1620) ${ }^{10}$ ) unter Nr. 14 und auf der Ansicht „Vera Effigies urbis Heidelbergae“ (1622) ${ }^{11}$ ) unter Nr. 38 östlich unterhalb des Jettenbühl, dort wo heute der Friesenbergweg in die Hauptstraße mündet, die alte Jakobskirche noch abgebildet; soweit sich erkennen läßt, war sie ein kleiner, geosteter gotischer Saalbau mit polygonalem Chorschluß, Zeltdach und Dachreiter sowie einem kurzen, eingezogenen Anbau mit niedrigem Zeltdach im Westen ${ }^{12}$ ).

Ubereinstimmend wird in den Quellen weiter betont, daß Kurfürst Philipp Wilhelm die neue Jakobskirche auf der Stelle der alten erbauen ließ; KAYSER nennt als Zeitpunkt des Baubeginns das Jahr 1685, aus der Portalinschrift geht das Jahr der Fertigstellung, 1688, hervor; und Hertwig gibt schließlich über die Höhe der Baukosten Aufschluß: 90000 Gulden waren für die damalige Zeit eine ungeheuere Summe. Von Kayser und Hertwig erfahren wir ferner, daß das neuerstellte Gotteshaus zunächst als katholische Pfarrkirche diente.

1689 brach der Erbfolgekrieg aus; auch die Jakobskirche blieb von seinen verheerenden Folgen nicht verschont. Aber die Zerstörungen waren keineswegs so ernst, wie man angenommen haben mochte, geschweige denn total. - Als sich unter der Herrschaft Johann Wilhelms allenthalben in der Pfalz die Kräfte des Wiederaufbaus zu regen begannen, dachte man auch daran, die Schäden an der Jakobskirche zu beheben. Im Januar 1697 begutachtete ein Beamter der Hofkanzlei den Zustand des Baus und

${ }^{8)}$ Thesaurus Palatinus, Bayerisches geheimes Haus-Archiv München, No. 317. S. $71 \mathrm{f}$.

9) Hertwig, S. 15.

$\left.{ }^{10}\right)$ Im Kurpfälzischen Museum Heidelberg.

11) Im Kurpfälzischen Museum Heidelberg.

12) Zur alten Jakobskirche vgl. Oechelhatuser, a.a.O., S. 115. Oechelhaeuser weiß zu berichten, daß die gotische Jakobskirche in der Reformationszeit verfiel und nachher als Geschützhaus verwendet wurde. Falsch ist die Behauptung, die Kirche sei 1685 restauriert und ihre Gewölbe 1688 von einem Italiener für $2000 \mathrm{fl}$. ausgeschmückt worden. Das Datum 1685 und die letztgenannte Tatsache sind vielmehr auf die neue Jakobskirche Philipp Wilhelms $\mathrm{zu}$ beziehen. 
berichtete dem Kurfürsten: „Über die Beschaffenheit des gewölbs auf dem Chor und Sacristey in St. Jacobs Kirchen zu Heidelberg habe ich unter Zuziehung des Werckmeisters Adam aufm Schloß alda den augenschein eingenommen ... Belangend nun die Bedachung eingangs gemelter Zwey gewölber, hat genannter Meister Adam solche etwas pretios, und zwar mit einem großen tachstuhl, wozu etliche und vierzig stamm Holtz verbraucht werden müßten, vorgehabt, mein ... vorschlag aber ware, daß die bedeckung ohne tachstuhl mit drey Mauerlatten ... . usw. ${ }^{13}$ ). Und am $10 . \mathrm{Fe}-$ bruar desselben Jahres schreibt ein kurfürstlicher Beamter namens Dellinger an seinen Herrscher: „... seye Befelcht worden, mit Zuziehung eines daß Wercks Verständigen leuthen daß gewölb ahn Chor, in der S. Jacobs Kirchen zu Heydelberg mit einem genauen überschlag Besichtigen, und einschicken... lassen solte, so berichte darauf gehorsambst, daß niemand anders hierzu tüchtig zu sein erachtet, alß eben den Bauw Meister selbst Karaski, welcher aber bey der ersten visitation nit inheimisch geweßen, umb so weniger, dann auch wissen können was Hirrzu ahn Borden ... nöthig hatte, dahero seine ahnkunft erwarten müssen ..." ${ }^{14}$ ). - Diese beiden entscheidend wichtigen Briefe sollen weiter unten interpretiert werden.

Die beabsichtigten Reparaturen kamen, wie wir sehen werden, nicht zustande. Eiligere Bauunternehmungen mögen dazwischen gekommen sein oder, was wahrscheinlicher ist, das nötige Geld wird gefehlt haben. Es lag natürlich im Interesse der kurfürstlichen Verwaltung, daß die Heidelberger Bauwerke so rasch als möglich wiederhergestellt wurden. Nun war es nicht leicht, zahlungskräftige Bauherren zu finden, die in die Tat umzusetzen vermochten, was der mittellosen Administration zu schaffen versagt blieb. Kurfürstliche Räte gaben den Weinheimer Beschuhten Karmeliten den Ratschlag, Johann Wilhelm um die Uberlassung der Jakobskirche zu bitten ${ }^{15}$ ). Aber der Kurfürst bewilligte diese Bitte nicht; er befahl vielmehr den Beschuhten Karmeliten, in ihrem Weinheimer Kloster zu bleiben, dekretierte jedoch gleichzeitig, daß die Unbeschuhten Karmeliten die Kirche erhalten sollten, „umso mehr...., als diese im besseren Stand den Klosterbau aufzuführen sich befinden " ${ }^{16}$ ). - Die Unbeschuhten Karmeliten hatten nämlich, auf die Absicht der Beschuhten aufmerksam geworden, ihrerseits die Jakobskirche beantragt und, um dem Antrag das erwünschte Gehör zu verschaffen, ihre guten Beziehungen zum Kaiserhaus in Wien spielen lassen. Sicher hat die Empfehlung durch die Kaiserin, Johann Wilhelms Schwester, zum Entschluß des Kurfürsten beigetragen. Der „Kurpfältzische geheime- und Regirungs-Rath Morass" unterrichtete in der Angelegenheit den Kaiser, "daß die Kirche zu S. Jacob vom Kurfürsten Philipp Wilhelm ganz neu aufgebauet, in diesen letzten Krieg aber das Dach weggebrannt worden, sonst aber in guten Stand" sei und verfehlte nicht, mit Nachdruck zu bemerken, daß „jedoch gar keine Fundation dabey sey“ ${ }^{17}$ ). Das Fehlen jeden Kapitals sollten die Karmelitenmönche noch oft zu spüren bekommen. - Zunächst machten sich drei Brüder ans Werk: „Ihre erste Arbeit war, das Chor, das am wenigsten Beschädiget war, zum Gottesdienst zuzurichten. Sie ließen dieß durch eine schwache Mauer von dem Langhause absondern. Das Chor enthielt alles, was der katholische Gottesdienst bedarf. An dem Chor war ein sogenanntes Oratorium angebaut, worinn Kurfürst Philipp Wilhelm dem Gottesdienst beywohnte, und seiner

13) GLA Karlsruhe 204/47: Acta. Die reparation deren Häusseren Zu Heydelberg btr.: Kirch und Kirchenhöfen, auch applanirung des Weegs auf d. Schloß betr. 1688-1796. S. 15.

14) GLA Karlsruhe 204/47, S. 26.

15) Hertwig, S. 18/19. 16) Hertwig, S. 23.

17) Hertwig, S. 25. 
Andacht oblag. Dieses ließen sie sammt dem Chor decken, und darinn ihre Wohnung zurichten... In der Kirche ward der erste feyerliche Gottesdienst an dem Feste der heiligen Therese gehalten, wobey ein Jesuit predigte" (15. Oktober 1701) $\left.{ }^{18}\right)$. - Aus diesen Zeilen erhellt, daß der Chor 1697 nicht unter Dach gebracht worden war.

Noch im ersten Jahrzehnt des 18. Jahrhunderts erhielt das aufblühende Kloster seinen eigenen Baumeister, den Laienbruder Dominicus von der h. Euphrosina. Ihm waren von nun an Planung und Überwachung aller klösterlichen Bauunternehmungen aufgetragen ${ }^{19}$ ). - Freilich zwangen die beschränkten Mittel die Mönche zu äußerster Sparsamkeit. Doch nach und nach wurde die Jakobskirche instand gesetzt bzw. den Bedürfnissen der Klosterleute angepaßt. 1709 ließ Vicar Fridolin „in dem Chor, der nur in der Mitte ein Fenster hatte, um ihm mehr Hellung zu verschaffen, auf beyde Seiten größere Fenster setzen " ${ }^{20}$ ), und 1712 endlich wurde unter dem Priorat des rührigen Pater Justinian das Laienhaus der Kirche gedeckt: „Die von dem Feuer beschädigten Seitenmauern droheten den Einsturz. ... Die einzige Rettung bestand darinn, daß sie (die Kirche) ohne Verschub gedeckt werde“ ${ }^{21}$ ). Der Mannheimer Stadtzimmermeister Heinrich Wilhelm Warth besorgte die Zimmerarbeit zur Zufriedenheit aller: „Nach aufgeschlagenem Dache sah man die meisterhafte Arbeit. Das Ganze bestehet aus einem Hangwerk, welches die, durch den Brand geschwächten Mauern mehr zusammenhält, als beschweret“" 22 ). 1712 wurden auch die Kirchenfenster eingesetzt. Der Chronist erwähnt ausdrücklich: „Die eisernen Rahmen, das Bley, der Arbeitslohn, ohne das Glas kosteten dreyhundert Gulden “ ${ }^{23}$ ). Offensichtlich waren keine Anderungs- und Ausbesserungsarbeiten nötig, die ein Steinmetz oder Maurer hätte ausführen müssen. - Prior Justinian ließ das Langhaus nicht nur erneuern; er nützte die günstige Gelegenheit, um unter ihm „eine Todtengruft oder sogenannte Crypta" einrichten zu lassen. Beim Ausschachten trafen die Arbeiter „in der Mitte dieser Gruft das Fundament oder ein Überbleibsel der ehemaligen St. Jacobskapelle" an ${ }^{24}$ ). - Die provisorische Scheidemauer zwischen Chor und Laienhaus fiel noch während Justinians Amtszeit. Unter Prior Philipp wurde 1715 der Kirchenfußboden mit steinernen Platten belegt und die Kommunionbank erstellt ${ }^{25}$ ). „Die Kirche war nun von außen vollendet, und im Innern, so viel der Gottesdienst nothwendig erforderte eingerichtet" ${ }^{26}$ ).

Die Mönche konnten jetzt an den Bau ihres Klosters gehen; Bruder Dominicus von der h. Euphrosina fertigte den Riß: die "mustergültige" Zeichnung trug ihm allgemeine Anerkennung ein. Am 20. November 1718 legte der Kurfürst feierlich den Grundstein zum Klosterneubau; rasch kamen die Arbeiten in Fluß; im August 1719 standen „die äußern Mauern des neuen Klosters untern Dache, welches Ziegel bedeckten" ${ }^{27}$ ).

Der Innenausbau des Klosters und die Ausstattung der Kirche waren von nun an die Hauptanliegen der Mönche. Uber den 1722 angeschafften Hochaltar wird im Rahmen der Besprechung der Ausstattung gehandelt werden; der Hofschreiner Sigismund Zeller, der diesen Altar ausführte, wurde 1735 - inzwischen hatte er es zum Hofbaumeister gebracht - zu einer anderen Arbeit herangezogen: Kurfürst Karl Philipp wünschte, daß die Leichname des Pfalzgrafen Joseph Karl und dessen Gemahlin (sie waren in der "gemeinen Gruft" der Karmelitenkirche beigesetzt) eine
18) Hertwig, S. 28.
19) Hertwig, S. 33.
20) Hertwig, S. 36.
21) Hertwig, S. 37.
22) Hertwig, S. 41.
23) Hertwig, S. 44.
24) Hertwig, S. 44.
25) Hertwig, S. 46.
${ }^{26}$ ) Hertwig, S. 48.
27) Hertwig, S. 49 f. 
eigene, würdigere Ruhestätte erhalten sollten. Im August 1735 kam Hofbaumeister Zeller mit dem Auftrag nach Heidelberg, eine günstige Stelle für eine Fürstengruft auszusuchen; er berief „einen anderen Baumeister Namens Hofer, mit welchem er den Platz zwischen dem hohen Altar und der Communicantenbank abmaß..."; Mitte September fing man an, die Gruft auszuheben: „Bey dieser Gelegenheit dachte der Prior auch ein Begräbnis für seine Verstorbenen Mitbrüder, nach Ordensbrauche einrichten zu lassen. Sein Vorhaben gelang... Die Arbeit ward dabey so fleißig betrieben, daß schon vor Weihnachten alles nach Wunsch fertig war... Im Jahre 1736 ward der hohe Altar wieder aufgerichtet". Die sterblichen Uberreste des Pfalzgrafen, der Pfalzgräfin und ihrer fünf frühverstorbenen Kinder wurden feierlich in die neue Fürstengruft überführt ${ }^{23}$ ).

Für die Jahre zwischen 1736 und 1764/65 sind uns keine Bauunternehmungen an oder in der Kirche überliefert; dagegen erfahren wir von einer Klostererweiterung in den Jahren $1753 / 54^{29}$ ). Etwa $1764 / 65$ ersetzte man dann die unansehnliche Orgelempore: „In der Kirche ober der Hauptthüre war eine Emporkirche, ein sogenanntes Odeum, ein Platz für die Orgel angebracht. Dieses Odeum bestand aus rauhen, von der Zeit geschwärzten Brettern. Die Bauregel erforderte eine Emporkirche aufzuführen, die mit der Größe und Schönheit übereinstimmt“" ${ }^{30}$ ). Die Bauregel wurde wohl erfüllt, aber das Kloster hatte in der Folgezeit schwer an den entstandenen Schulden zu tragen. Immerhin: etwa ein Jahrzehnt später entschloß man sich, „die Kirche und das Kloster“ ausweißen zu lassen. Italienische Handwerker führten mit vielbewundertem Geschick die Malerarbeit aus: „Die steinernen Fensterrahmen wurden mit Leimwasser blaulecht, und die Communicantenbank mit Oehlfarb angestrichen " 31 ). Im Anschluß an die Ausweißung wurden die Kirchenfenster - sie „bestanden aus kleinen runden, von der Sonne schon größten Teils dunkel gebrannten Scheiben“ durch „neue Fenster mit langen Scheiben“ ersetzt ${ }^{32}$ ) und schließlich unter Prior Johann vom Kreuze 1781 die Kirche, „die von außen noch in rauhen Steinen dastand, gegen die Straße und den Hof zu mit Speise beworfen und weiß angestrichen". „In die leere Nische, die am Frontispicium der Kirche angebracht war, ließ er (Prior Johann vom Kreuze) die Statue des h. Jacobs als Kirchenpatron setzen; wofür der Heidelberger Bildhauer Düger hundert fünf und fünfzig Gulden empfing “ ${ }^{33}$ ). Aus eigenen Mitteln konnten die Mönche die Durchführung all dieser Arbeiten kaum bestreiten; sie baten deshalb den Kurfürsten „um beysteuer zur reparation ihre Kirch und Klosters"; in einem in dieser Angelegenheit von einem Bausachverständigen verfaßten, an den Kurfürsten gerichteten Brief wird die Verputzung dringend empfohlen, „weil die Kirche von Ihrer ersten Entstehung unverbutzet dastehet, wo zu malen die vordere Hauptfacade dem wetter ausgesetzet ist, . . . die Steinhauer und herrlich bildhauer arbeit in die Länge verfallen müßte..."; desweiteren wird erwähnt, es „solle in die obere Muschel der Hauptfacade das Bildnis des heiligen Jacobs, auf die beide seithen der Verdachung aber 2 Piramiden Von stein, dan auf die Verdachung ein großes Creutz mit streben Von eisen gestellet werden “ $\left.{ }^{34}\right)$. Ob der beantragte $\mathrm{Zu}$ schuß genehmigt und ob die letztgenannten Pläne verwirklicht wurden, war nicht herauszufinden.

${ }^{28)}$ Hertwig, S. 106 f. ${ }^{29}$ ) Hertwig, S. 184.

32) Hertwig, S. $246 .{ }^{33}$ ) Hertwig, S. 256.

30) Hertwig, S. 191. 31) Hertwig, S. 207.

${ }^{34}$ ) GLA Karlsruhe 204/1956: Carmeliten Convent um beysteuer zur reparation ihre Kirch und Klosters. 1781. 
Die Mönche sollten sich ihrer so mühsam hergerichteten Kirche nicht mehr lange erfreuen. - 1793 warf die französische Revolution ihre ersten Schatten: „Österreichische Legionen und ihre Bundesgenossen zogen in die Pfalz, und in Heidelberg richteten sie ihre Magazinen ein. Da die bürgerlichen Wohnungen nicht hinlänglichen Raum dafür anbothen, so wurden katholische Kirchen dazu bestimmt; nämlich die Kirche des katholischen Spitals (St. Annakirche, Anm. d. V.); die Kirche der Dominicaner, jene der ehemaligen Jesuiten, und die St. Jacobskirche. Das Langhaus derselben wurde von dem Chor - worinn der Gottesdienst gehalten wurde durch eine bretterne Wand abgesondert, und darinn mehr als achttausend Malter Früchten aufgehäuft" ${ }^{35}$ ). Dem Kloster schien ein anderes Schicksal bevorzustehen: in Heidelberg fehlten zur Unterbringung von Verwundeten geeignete Räume; „man berathschlagte daher entweder das Karmelitenkloster oder das Collegium der ehemaligen Jesuiten, welches nach diesen die Lazaristen bewohnten, zu diesem Behufe einzurichten. Das Loos fiel auf das Collegium“" ${ }^{36}$ ).

Was der Krieg nicht vermochte, das vermochte die Säkularisation; sie setzte dem Bestand des Karmelitenklosters unnachsichtig ein Ende. Der Kurfürst Maximilian Joseph konnte noch eben rechtzeitig die Särge mit den sterblichen Uberresten seiner Verwandten „in aller Stille aufpacken und in der Nacht auf Gutwägen nach München führen lassen“, mußte er doch, wie Pater Hertwig verbittert bemerkt, fürchten, daß sie "auch als eine Verlassenschaft der Karmeliten angesehen, und also in einer Auction dem Meistbiethenden zugeschlagen werden " könnten ${ }^{37}$ ).

Am 31. März 1809 wurden die Mönche rücksichtslos aus dem Kloster vertrieben. Das Inventar der Kirche wurde versteigert, der Bau anschließend geschleift. Als Krönung der Aktion hatte man sich ein mutwillig-naives Schauspiel ausgedacht; der Heidelberger Schuhmachermeister Johann Joseph Eckertt erzählt uns in seinem 1866 verfaßten Tagebuch die unerfreuliche Episode recht anschaulich: „Die Kirche war abgebrochen, aber der Thurm stand noch allein; nun wollten die Baumeister den Thurm auf einmal umlegen, um da der Welt ein großes Schauspiel aufzuführen. Der Thurm ward demnach unten zur Hälfte abgeschlagen und wieder mit Balken gestützt. Der Tag dieser Sehenswürdigkeit wurde bekannt gemacht ...., wurde eine Tribüne im Carmitter-Wäldchen erbaut; daß das ganze Carmitter-Wäldchen von Menschen wimmelte... Es ward ein großes Feuer unten am Thurm angezündet, so daß die Stützbalken... in Flammen geriethen, ... und so mußte sich demnach, da nach Verbrennung der Balken keine Stütze mehr nach dem Ermessen der Baumeister vorhanden war, der Thurm ganz majestätisch umlegen, aber fehlgeschossen. Als die Stützen verbrannt waren, löste sich die Hälfte des Thurms los und rutschte... auf den Boden, während die andere Hälfte wie gespalten stehn blieb und mußte mit großer Gefahr später abgebrochen werden “ ${ }^{38}$ ).

Wie über hundert Jahre früher der Pulverturm des Schlosses, so trotzte der Turm der Karmelitenkirche zunächst der Zerstörung. Diesmal freilich machten sich rasch Hände ans Werk, „um sogar das Andenken zu vertilgen, daß jemals Ordensmänner da wohnten" $\left.{ }^{39}\right)$.
35) HeRtwig, S. 384.
36) Hertwig, S. 394.
37) HERTWIG, S. 424.

${ }^{38}$ ) Oskar Huffschmid: Aus dem Tagebuch des Johann Joseph Eckertt. Neues Archiv für die Geschichte der Stadt Heidelberg, X, 1913, S. 52.

$\left.{ }^{39}\right)$ Hertwig, S. 420. 


\section{Die Baumeisterfrage}

Welche kunstgeschichtlichen Folgerungen lassen sich nun aus dem bisher Ausgeführten ziehen?

Zunächst wohl eine sehr entscheidende: Die Karmelitenkirche St. Jakob ist mit der 1685-1688 unter Kurfürst Philipp Wilhelm aufgeführten St. Jakobskirche identisch. Die Karmelitenmönche haben weder ein neues Gotteshaus gebaut, noch das übernommene wesentlich verändert; sie haben es lediglich wiederhergestellt. Mag diese Wiederherstellung auch hie und da eigene Wege gegangen sein: für eine ins Gewicht fallende Selbständigkeit der Erneuerer fehlen alle Anzeichen. Abgesehen von der Zurückhaltung der Karmeliten gegenüber jedem Bauluxus und Bindungen an bestimmte Bauformeln, hätten die beschränkten Geldmittel einen tiefer greifenden Umbau auch gar nicht erlaubt. - Wenn die St. Jakobskirche aus dem 17. Jahrhundert aber als Karmelitenkirche weiterbestanden hat, so haben wir in den bekannten Abbildungen (Abb. 1, 2, 4) zugleich weitgehend verbindliche Abbildungen der Jakobskirche Philipp Wilhelms vor uns.

Kann nun, da sich die Erbauungszeit 1685-1688 ergeben hat, Breunig als Architekt noch in Betracht kommen? - Die oben zitierten Schriftstücke aus dem Jahre 1697 beantworten diese Frage meines Erachtens ganz klar. Da berichtet zunächst ein Baubeauftragter der Hofkanzlei von seiner Visitation der zerstörten Chor- und Sakristeidächer der Jakobskirche. Er erwähnt seinen sachverständigen Begleiter „Werckmeister Adam aufm Schloß"; es kann sich da natürlich um keinen anderen handeln als um Adam Breunig ${ }^{40}$ ). Breunig rät, „einen großen tachstuhl“ aufzuschlagen, stößt aber gleich auf den Widerspruch des kurfürstlichen Beauftragten. Dem scheint eine schlichte Notlösung angemessener als eine aufwendige, geldverschlingende Konstruktion. (Breunigs Vorliebe für übertrieben stabiles Dachwerk - man denke nur an das Schwetzinger Schloß, die Alte Universität und die Jesuitenkirche - tut sich in diesem Falle bereits einprägsam kund.) Allein aus der kleinen Episode ließe sich schon der Schluß ziehen, daß Breunig nicht der Baumeister der Jakobskirche gewesen sein kann; man hätte dem Rat des Schöpfers eines Bauwerks unzweifelthaft mehr Bedeutung beigemessen, wenn es darum ging, das Bauwerk wiederherzustellen. Zudem hätte der Kurfürst schwerlich einem "Maurer" die Gestaltung eines wichtigen Baus übertragen ${ }^{41}$ ). Der von Dellinger unterschriebene Brief bestätigt diese Gedankengänge; Dellinger betont nachdrücklich, daß schließlich kein anderer geeigneter sei, die Instandsetzung zu besorgen, als eben der „Bauw Meister selbst Karaski“; der sei unglücklicherweise zum Zeitpunkt der ersten Visitation (Dellinger meint ohne Frage die im ersten Schriftstück erwähnte; sicher war jener Visitator, der von Breunig begleitet wurde, einer der Untergebenen Dellingers) verreist gewesen. Er habe daher seine Ankunft erwarten müssen, um endlich aus berufenem Munde verläßliche Auskunft über die Menge des zu beschaffenden Holzes zu erhalten.

Der Schöpfer der Jakobskirche war also Karaski. Wir kennen Heinrich Charrasky (so schreibt sich der Künstler selbst) als wichtigen, um den Wiederaufbau des zerstörten Heidelbergs verdienten Künstler sehr wohl. Siebzehnjährig war er, laut LoHMEYER, im Jahre „1673 aus Ungarn als verfolgter Protestant geflohen und wie Breunig bereits vor der Zerstörung in Heidelberg ansässig gewesen, von wo er mit seiner

${ }^{40}$ ) Breunig wohnte damals auf dem Schloß. Vgl. RicDl, Heidelberger Jesuitenkirche, S. 86.

41) Vgl. RiEdL, Heidelberger Jesuitenkirche, S. 86 f. 


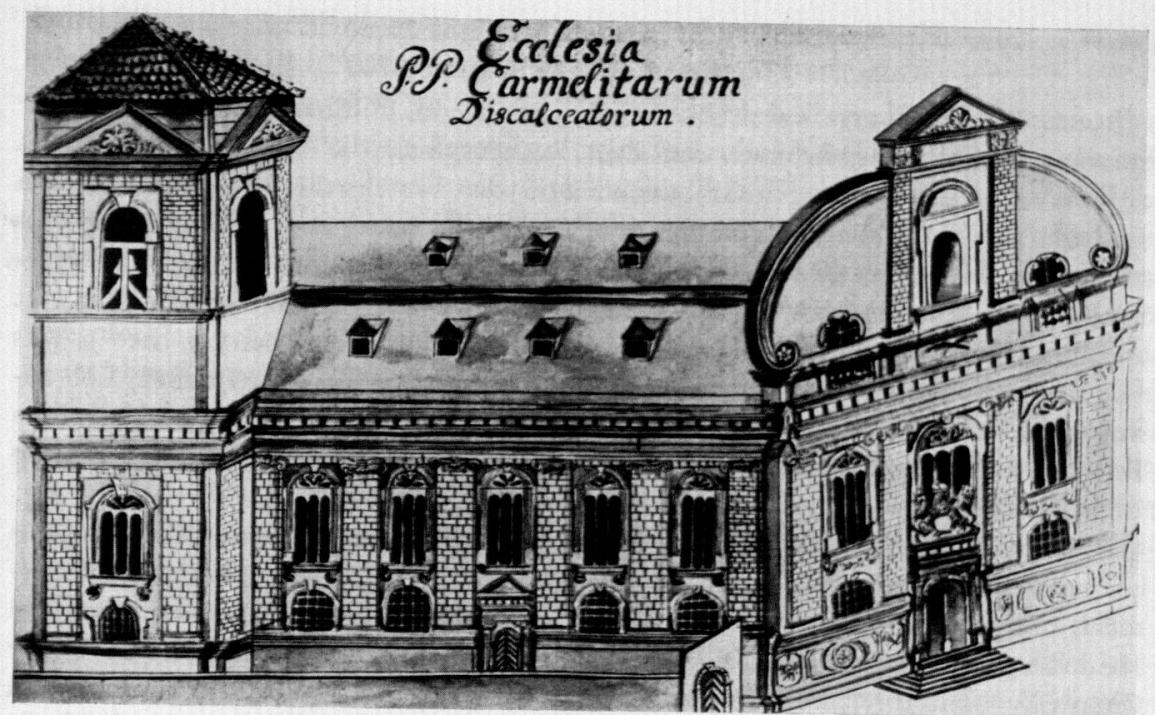

Abb. 1. Heidelberg, Karmelitenkirche St. Jakob: Ansicht von Nordwesten her. Zeichnung von Gottfried Thum im Thesaurus Palatinus, um 1750

Monasterium P.P. Carmelitarum Discaliceatorum.

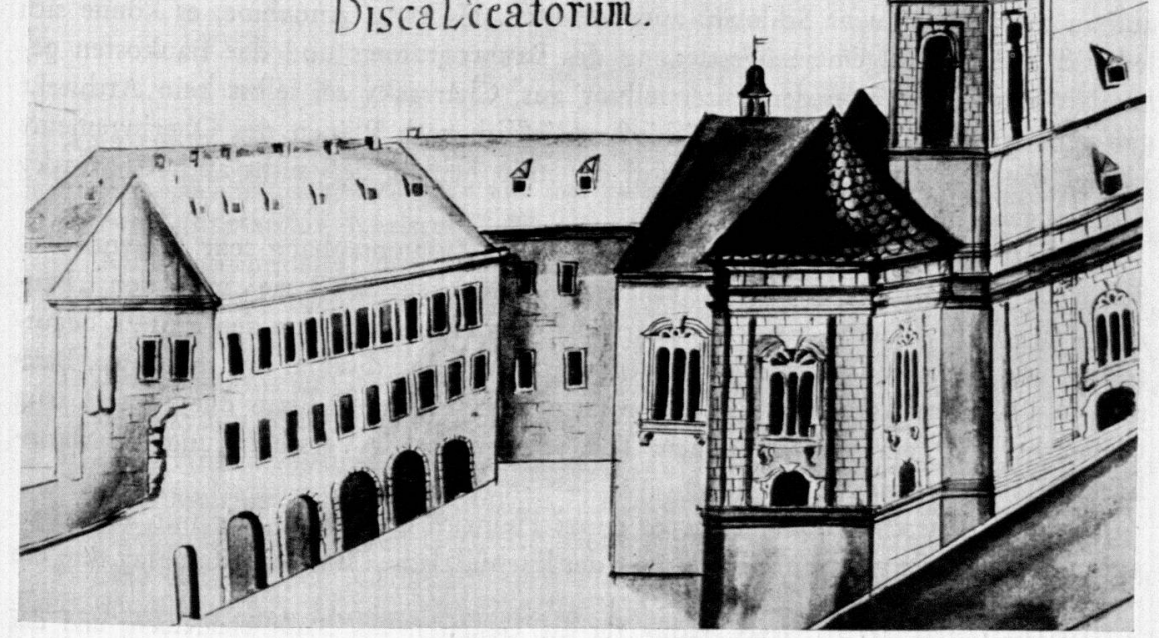

Abb. 2. Heidelberg, Karmelitenkirche St. Jakob: Ansicht von Nordosten her. Zeichnung von Gottfried Thum im Thesaurus Palatinus, um 1750

Familie dann nach Wimpfen im Tal geflüchtet war. Seine eigene, von ihm verfertigte marmorne Büste stand 1805 und noch lange ins Jahrhundert hinein im Garten des neuen evang.-luth. Hospitals in der Plöck, dessen Wohltäter er war; sie ist jetzt verschwunden. - Rückwärts trug sie diese Inschrift: 


\section{,Henricus Charrasky, statuarius, natus Anno 1656 in}

Gomorra Hungariae. Ipse fecit. Anno 1709.“ “ 42 ).

LOHMEYER hat Charrasky als Bildhauer, und nur als Bildhauer herausgestellt; er hat ihm den Herkules-Brunnen auf dem Rathausplatz, die Risalitdekoration des "Riesen“ und das Venningen-Grabdenkmal in der Pfarrkirche zu Neidenstein bei Sinsheim zuweisen können, ausnahmslos Werke, die nach dem Erbfolgekrieg entstanden sind. LOHMEYER hat andererseits aber darauf aufmerksam gemacht, daß Kurfürst Johann Wilhelm schon 1692 Charrasky einen „so excellenten Künstler“ genannt und ihn mit Arbeiten für das Schloß Bensberg (bei Düsseldorf) betraut hat ${ }^{43}$ ). Was mag den in künstlerischen Dingen so sehr verwöhnten Kurfürsten zu seinem Lob bewogen haben? Auf welche Weise hatte sich Charrasky seinen Ruf erworben? Eine Teilantwort scheint jetzt möglich: als Baumeister im Dienste des Kurfürsten Philipp Wilhelm.

Es ist bekannt, daß Charrasky um 1700 dem kurpfälzischen Bauamt als Bauschreiber vorstand; die anderen beiden Beamten waren zu dieser Zeit „Baumeister" Sartorius und „Werckmeister" Breunig ${ }^{44}$ ). Aus den Akten über den Wiederaufbau des Heidelberger Schlosses ${ }^{45}$ ) läßt sich nun folgendes erschließen. Schon Mitte 1690 war Charrasky "Bauschreibereiverweser" ${ }^{46}$ ) und ein Jahr darauf „Bauschreiber " ${ }^{47}$ ); in dieser Eigenschaft war er in der Folgezeit ständig mit der Planung und Überwachung der Reparaturen an den Schloßgebäuden beschäftigt. Verschiedene Werkmeister standen ihm zur Seite, seit dem Juni 1696 auch der eben nach Heidelberg zurückgekehrte „Maurermeister" Breunig ${ }^{48}$ ). Für die Jahre 1698/99 ist eine interessante Planungstätigkeit Charraskys belegt; der Künstler hatte damals Pläne für einen Wiederaufbau des Schwetzinger Schlosses auszuarbeiten. Martins Annahme, es könne sich lediglich um eine allgemeine Festlegung des Bauprogramms und der Baukosten gehandelt haben, geht von der Unterstellung aus, Charrasky sei selbst kein Architekt gewesen; wenn das Schwetzinger Schloß schließlich nach Plänen des Oberingenieurs Flemal wiederaufgebaut wurde, so will das nicht heißen, daß nicht auch Charrasky Risse eingereicht hatte ${ }^{49}$ ).

Die Akten verraten uns noch etwas in unserem Zusammenhang sehr Wesentliches. Seit 1700 war das Mannheimer Rathaus im Entstehen; 1703 rief man den „Bauschreiber und Bildhauer" Heinrich Charrasky von Heidelberg, um den Bau zu begutachten, und 1705 wandte man sich erneut an Charrasky, diesmal mit der Bitte, Bauplan und Kostenvoranschlag zum Turm zu prüfen. Mit einer Figur der Justitia trug Charrasky 1709, ein Jahr vor seinem Tod, selbst noch zur Verschönerung des Mannheimer Rathauses bei ${ }^{50}$ ).

Alle diese Tatsachen dokumentieren eines: Heinrich Charrasky war mit dem Bauwesen aufs innigste vertraut; als Beamter der kurpfälzischen Baubehörde oblag ihm die

${ }^{42}$ ) Karl Lohmeyer in: Neues Archiv für die Geschichte der Stadt Heidelberg und der rheinischen Pfalz, XI. Heidelberg 1924. S. 155.

43) Ebenda S. 154.

${ }^{44)}$ Vgl. RiedL, Heidelberger Jesuitenkirche, S. 86 f.

${ }^{45}$ ) Exzerpte in: Mittheilungen zur Geschichte des Heidelberger Schlosses, III. Heidelberg 1896. S. $1 \mathrm{ff}$.

$\left.{ }^{46}\right)$ Ebenda Nr. 230. ${ }^{47}$ ) Ebenda Nr. 252. ${ }^{48}$ ) Ebenda Nr. 323.

49) Kurt Martin: Die Kunstdenkmäler des Amtsbezirks Mannheim, Stadt Schwetzingen. Karlsruhe 1933. S. 25 f.

50) Friedrich Walter: Bauwerke der Kurfürstenzeit in Mannheim. Augsburg 1928. S. 49. 
Durchführung verschiedener Unternehmungen, als Gutachter in Architekturfragen genoß er die Wertschätzung auswärtiger Bauherren.

Man darf sich eben nicht an seinem Titel „Bauschreiber" stoßen. Ein Bauschreiber brauchte keineswegs nur eine Administrativperson zu sein; der spätere Hofbaumeister Wachter war 1665 als „Bauschreiber" in kurfürstliche Dienste getreten ${ }^{51}$ ) und Sigismund Zeller, ein Nachfolger Breunigs, führte 1739 neben seinem Titel „Hofbaumeister" auch den Titel "Bauschreiber und Baucommissar" ${ }^{52}$ ). Man darf zweitens aus dem Tatbestand, daß Charraskys beglaubigte Werke aus der Zeit nach dem Erbfolgekrieg doch ausnahmslos Skulpturen sind, daß er in den Akten immer wieder als „Bildhauer" bezeichnet erscheint, ja daß er sich selber „statuarius" nennt, keinen voreiligen Schluß ziehen. Charrasky war von Haus aus gewiß ein Bildhauer; seine Tätigkeit als solcher wird sich sicherlich ganz besonders in der Epoche des Wiederaufbaus des zerstörten Heidelbergs entfaltet haben. Aber es ist ebenso offenbar, daß der Künstler dem Bauwesen eng verbunden blieb und bleiben mußte, auch dann noch, als die Bildhaueraufträge sich häuften.

Unsere neuerworbene und zunächst doch sehr überraschende Kenntnis von Charrasky als dem Erbauer der Karmelitenkirche läßt sich ohne $Z_{\text {wang mit }}$ dem vereinbaren, was sonst über den Künstler zu ermitteln ist. Die Personalunion BildhauerArchitekt war im Barockzeitalter durchaus geläufig; es genügt, die berühmten Namen Lorenzo Bernini, Andreas Schlüter und Ägid Quirin Asam zu nennen.

Sehr schwierig ist nun die Bestimmung des Architekturstils Charraskys; schwierig, weil das Aussehen der Karmelitenkirche nicht so genau überliefert ist, wie es wünschenswert wäre.

\section{Baubeschreibung}

Als Grundlagen der folgenden Ausführungen dienen:

1. Ein Plan der Klosteranlage aus der zweiten Hälfte des 18. Jahrhunderts (Generallandesarchiv Karlsruhe; Baupläne, Heidelberg, Nr. 70. Umzeichnung des Kirchengrundrisses: Abb. 3).

2. Ein Plan des östlichsten Stadtteil Heidelbergs, sign. „P. F. de Walpergen“, aus der zweiten Hälfte des 18. Jahrhunderts (Kurpfälzisches Museum Heidelberg).

3. Ein schematischer Grundriß der Kirche aus der Zeit um 1735 (Bayerisches Hauptstaatsarchiv München; Pfalz-Neuburg, Akt 1685) ${ }^{53}$ ).

4. Zwei Ansichten der Kirche, „Ecclesia P. P. Carmelitarum Discalceatorum" und "Monasterium P. P. Carmelitarum Discalceatorum“, im "Thesaurus Palatinus", gezeichnet um 1750 von Gottfried Thum (vgl. Anm. 8; Abb. 1 und 2).

5. Eine Ansicht der Kirche auf dem Heidelberg-Prospekt von A. Schlicht, 1784 (Kurpfälzisches Museum Heidelberg. Abb. 4).

6. Die oben zitierten schriftlichen Quellen.

Auf Grund dieser Unterlagen läßt sich die Karmelitenkirche als ein geosteter Saalbau mit eingezogenem, absidial geschlossenem Chor, einem Turm im nördlichen Winkel zwischen Langhaus und Chor und einem Anbau an der entsprechenden Stelle

51) Vgl. RiedL, Heidelberger Jesuitenkirche, S. 89 f.

52) Vgl. Anm. 45; Nr. 470, 30. Juli 1739.

${ }^{53)}$ Ich danke Frl. Dr. A. Stemper, Heidelberg, herzlich für den Hinweis auf diesen Plan. 
der Südseite beschreiben. Im Grundriß traten Turm und südlicher Anbau gleich Querschiffarmen aus der Flucht der Langhausmauern.

Die Westwand der Kirche war als Fassade ausgebildet und beherrschte die Ecke Hauptstraße-Friesenbergweg; die Fassade hatte zwei Geschosse. So war das untere

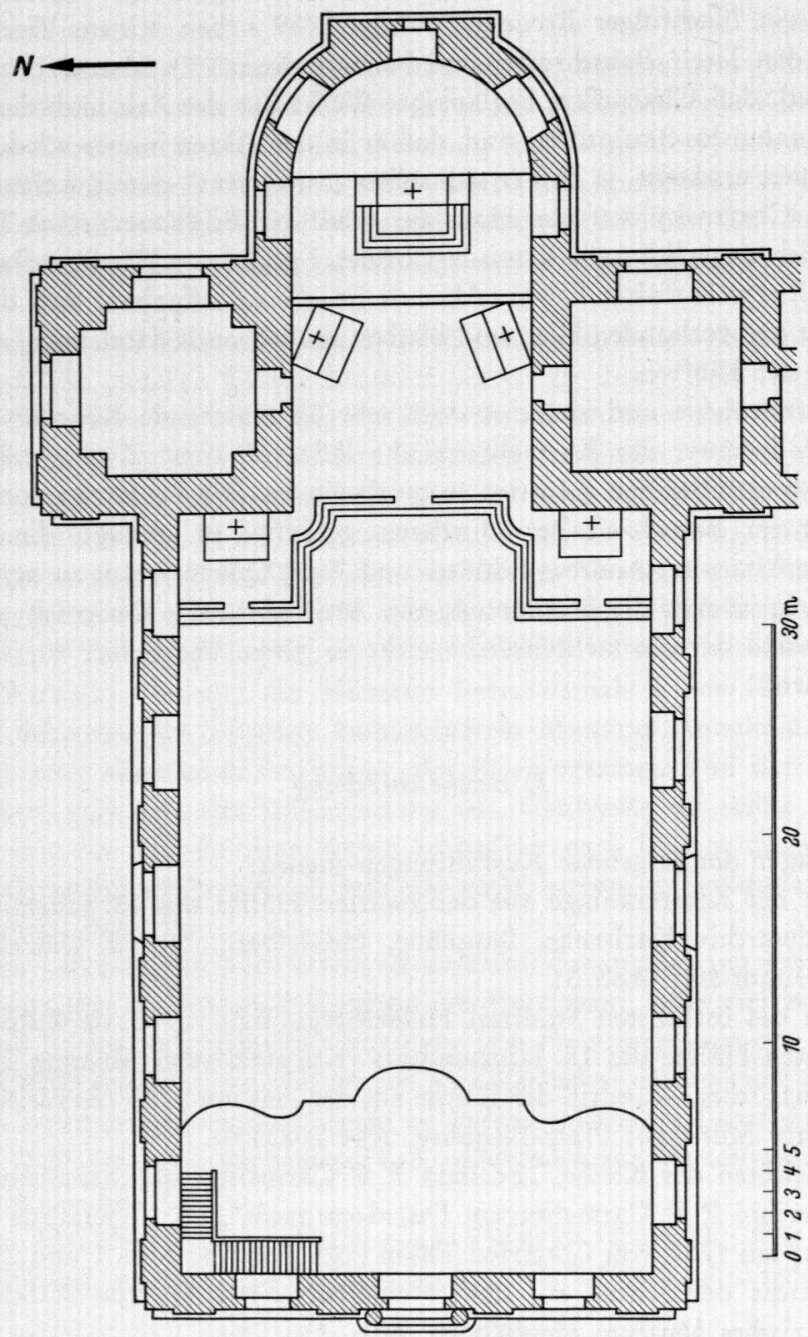

Abb. 3. Grundriß der Heidelberger Karmelitenkirche St. Jakob. Nach dem Plan im GLA Karlsruhe, umgezeichnet vom Verfasser

gegliedert: über einem hohen, nur vom Portal in der Mitte unterbrochenen Sockel mit Fuß- und Kranzgesims erhob sich die durch zwei sehr breite Pilaster mit jonischen Kapitellen in drei Felder geteilte Wand; Pilaster rahmten die beiden seitlichen, schmäleren Wandfelder außen. Ein mächtiges, nicht verkröpftes Gebälk schloß das Untergeschoß ab. - Der Sockel war reich durch geometrische, zum Teil ornamentüberzogene 
Füllungen belebt, das Portal als Säulenädikula mit einer rund- oder korbbogigen Ơffnung, einem hohen Gebälk und einem skulptierten Aufsatz (es handelte sich um die im "Thesaurus Palatinus" beschriebenen zwei Löwen mit dem kurfürstlichen Wappen und einer Inschriftafel) ausgebildet. Der Aufsatz ragte weit in das große Mittelfenster der Fassade hinein; dieses Fenster gehörte der oberen Ordnung an. Beide Ordnungen kamen an den Seitenteilen zur Geltung: unmittelbar über dem Sockel wurde die Wand da jeweils von einem ganz niedrigen, rund- oder stichbogigen Fenster mit Ohrengewände und Keilstein durchbrochen. Gleich darüber folgte jeweils ein hohes Fenster mit konsolengetragener Bank, profilierten Rahmenpfosten auf glatten Sockelstücken und einem Kopfrahmen, welcher mit seinen Ohren und seinem Keilstein demjenigen des kleinen unteren Fensters entsprach. Das Fenster über dem Portal glich formal den seitlichen Oberfenstern, war indessen etwas größer. Alle Fenster der oberen Ordnung waren durch zwei Pfosten dreigeteilt. Uber den Verbindungsbögen der Pfosten entwickelte sich Maßwerk: vier radialgestellte Glieder waren - genau wie bei der Jesuitenkirche - durch kleine Kleeblattbögen miteinander verkettet. - Das Fassadenobergeschoß bestand aus einem Sockel mit Kranzgesims (zugleich als Attika des Untergeschosses anzusprechen), einem mittleren pilastergerahmten und dreieckgiebelgekrönten Aufbau, der die Breite des unteren Mittelfelds hatte, und zwei großen, viertelkreisförmigen seitlichen Stützwänden. - Der Sockel (= Attika) war über den Pilastern des Untergeschosses verkröpft und über den Fenstern der unteren Seitenfelder in Balustraden aufgelöst; das Feld der Mittelädikula nahm eine große, segmentgiebelige Nische ein (in ihr stand seit 1781 Dücherts Jakobsfigur). Die Bogenkanten der Stützwände wurden von profilierten, unten zu rosettenbesetzten Voluten eingerollten Bändern gefaßt. Über den Balustraden befanden sich kleeblattförmige Fenster. Bleibt zu erwähnen, daß Ornamentreliefs das Sockelfeld unter der Nische (gekreuzte Palmwedel) und das Giebelfeld der Mittelädikula (Muschel- und Akanthusornament) zierten.

Die Langseiten der Karmelitenkirche zählten je fünf Fensterachsen. Sockel, Pilasterordnung und Gebälk der Fassade waren auch für die Gliederung der Langseiten verbindlich; nur war der Sockelfries nicht dekoriert. Fenstersystem und Fensterform entsprachen ganz genau denen der seitlichen Fassadenfelder; die Fenster waren in die Räume zwischen den Pilastern förmlich hineingezwängt, sie verzehrten so gut wie alle Wand. In der Mittelachse jeder Langseite war ein Adikulaportal mit Dreieckgiebel angeordnet. Der Turm war in seinem unteren Teil der Langseitengliederung entsprechend behandelt. Uber dem Hauptgesims folgte ein glattes, von schmalen Pilastern gerahmtes Geschoß (eine Art Mezzanin) und darauf ein hohes, allseits von breiten Lisenen eingefaßtes Stockwerk mit großen rundbogigen, nicht unterteilten Fenstern. Den Turm krönten vier stumpfe Dreieckgiebel und ein flaches Zeltdach auf einem niedrigen, hölzernen Geschoßstumpf; offensichtlich handelte es sich bei dieser Bedachung um ein Provisorium.

Uber die Außengliederung des Chors läßt sich kaum etwas aussagen. Thums Zeichnung (Abb. 2) ist sehr unzuverlässig; Thum wurde im allgemeinen mit der Perspektive schlecht, in diesem Fall aber überhaupt nicht fertig; die Verzeichnung - ein Vergleich mit dem Grundriß lehrt das auf den ersten Blick - ist grotesk. Im großen und ganzen ist dagegen das Bild von Schlicht (Abb. 4) vertrauenswürdig, wiewohl da auf Einzelheiten keine Rücksicht genommen ist. Immerhin läßt sich erkennen, daß, wie ja auch der Grundriß zeigt, das sonst halbkreisförmige Chorhaupt östlich mit einer 
platten, von einem kleinen Fenster durchbrochenen Wand schließt. Wird man in dieser seltsamen Formgebung etwa einen Beweis für die Wiederverwendung von Mauerteilen, zumindest aber von Fundamenten des Chorpolygons der gotischen Jakobskirche sehen dürfen? Die großen Chorfenster wurden erst 1709 geschaffen (vgl. oben) und waren formal (vielleicht darf man der Darstellung Thums in diesem Punkt Glauben schenken) den anderen Fenstern angepaßt.

Der südliche Anbau war genau so hoch wie Langhaus und Chor; er empfing durch ein großes Maßwerkfenster in der Ostwand Licht; an seine Südwand schloß sich (seit 1718/19?) ein Flügel der Klosteranlage.

Kompliziert war, der Schlichtschen Zeichnung nach zu schließen, die Dachzerfallung der Kirche: das Langhaus bedeckte ein Mansarddach, den Chor ein Sattel- mit anschließendem, östlich abgeplattetem Kegeldach und den Südanbau ein quer zur Kirchenachse gelagertes Satteldach; verschiedene Knickungen und Verschleifungen vermittelten zwischen den einzelnen Dachpartien. - Ob das Dach in dieser Gestalt den Zustand vor der Zerstörung wiederholte, ist natürlich nicht auszumachen.

Das Innere der Kirche war offenbar sehr schlicht; jedenfalls fehlt auf den erhaltenen Grundrissen jede Andeutung einer architektonischen Gliederung. Der große Langhaussaal hatte entweder eine Flachdecke oder ein niedriges Muldengewölbe. Einen beträchtlichen Raum nahm im Westen des Langhauses die (1764/65 erneuerte) Empore ein. Zugänglich war sie über eine Treppe im nordwestlichen Winkel; die Grundrißlinie der Brüstungsseite war bewegt.

Der Chor scheint gleich dem Langhaus ohne Wandgliederung gewesen zu sein; die (nicht näher zu bestimmenden) Gewölbe fußten vermutlich auf Konsolen. - Gegenüber dem Langhaus war die westliche Hälfte des Chorfußbodens zusammen mit den Plätzen vor den Wänden rechts und links des Choreingangs um zwei Stufen erhöht; dem Grundriß der Treppenanlage folgte die Kommunionbank. Die östliche Hälfte des Chorfußbodens war ihrerseits um zwei Stufen höher als die westliche. Aus dem Chor führten Türen in den Turm und in den Südanbau.

In unserem Zusammenhang verdient der oben unter 3. aufgeführte Kirchengrundriß im Bayerischen Hauptstaatsarchiv Beachtung. Es handelt sich um eine schlampige Skizze mit Eintragungen, welche sich fast ausschließlich auf die bestehende "gemeine" und die geplante Fürstengruft beziehen (die durch Falltüren verschließbaren Grufteingänge sind unter 2 und 8 im Langhaus und im Chor eingezeichnet). Auf diesem Grundriß sind nun punktierte, nur als Gewölbemarkierungen zu deutende Linien sichtbar: auf das Langhaus kommt ein großes Muldengewölbe (?), auf den Chor ein unechtes Tonnengewölbe mit Stichkappen. Sehr fragwürdig bleibt allerdings, ob mit den eingezeichneten Gewölben die Kirchengewölbe gemeint, oder ob nicht vielmehr die Deckenformen der beiden Grüfte angedeutet sind; für die letzte Möglichkeit spricht die Tatsache, daß im Chorgrundriß Pilaster markiert sind. Solche Wandvorlagen fehlen auf den beiden anderen erhaltenen Plänen; wenn sich aber die Pilasterandeutungen auf das Gruftgeschoß beziehen, wird es sich mit den Gewölbeandeutungen kaum anders verhalten.

Wie dem auch sei, eine schwere Deckenkonstruktion konnte für das Langhaus der Kirche nicht in Frage kommen, waren doch die Wände nicht besonders dick und ohne Widerlager ganz bestimmt nicht imstande, den Schub schwerer Gewölbe aufzufangen. Nicht umsonst wird in der Chronik eigens das „Hangwerk, welches die ... Mauern mehr zusammenhält als beschwert“ erwähnt. 


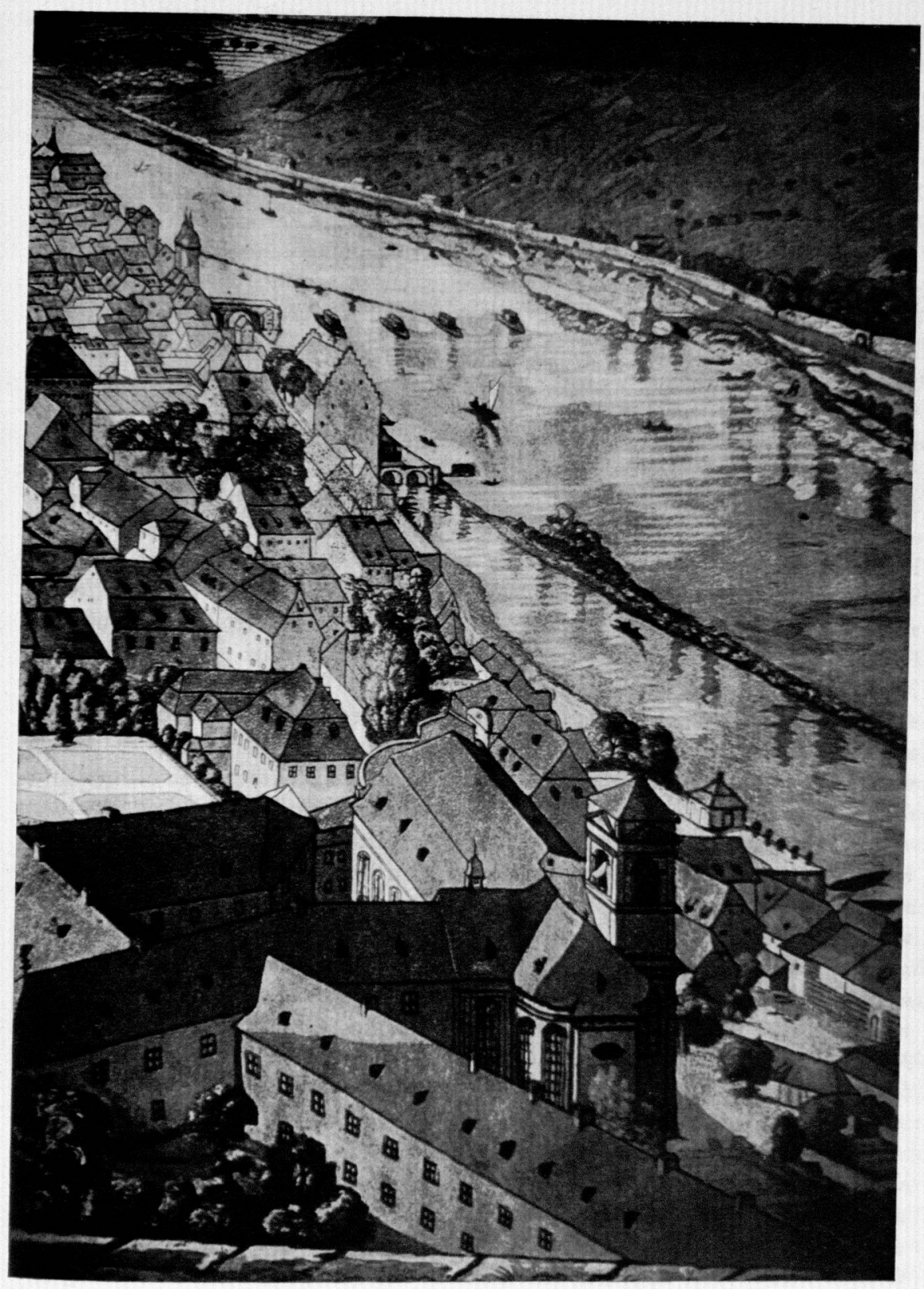

Abb. 4. Karmelitenkirche und -Kloster von Osten her. Ausschnitt aus dem Heidelbergprospekt von A. Schlicht, 1784

Der Münchener Grundriß gibt noch Aufschluß über die Verwendung des Turmuntergeschosses als Heiliggrab-Kapelle und des Südanbaus als "Cohr der geistlichen“; dieser "Cohr" war sicher das frühere „Oratorium ..., worinn Kurfürst Philipp Wil- 
helm dem Gottesdienst beywohnte“ (vgl. oben) und in dem die ersten Karmelitenmönche notdürftig hausten.

\section{Zur Stilfrage}

Wir müssen jetzt den Stil der Jakobskirche zu bestimmen versuchen, müssen prüfen, von welchen Voraussetzungen her die Kunstweise Heinrich Charraskys zu begreifen ist.

Der Gebäudetyp als solcher kann uns keinen Aufschluß geben: Saalkirchen mit eingezogenem Chor wurden im 17. Jahrhundert (genau so wie in früheren und späteren Jahrhunderten) überall gebaut, und die Position des Turms und des korrespondierenden südlichen Anbaus ist nichts, was uns eine bestimmte Fährte weisen würde. Uber die Innenarchitektur wissen wir zu wenig. Wir müssen uns folglich an die Außengliederung halten, was leider bedeutet, daß wir allein auf die Thumsche Zeichnung im Thesaurus Palatinus (Abb. 1) angewiesen sind.

Suchen wir nach Vergleichsbeispielen, so bietet sich der Stich mit dem Aufriß der deutsch- und wallonisch-reformierten Doppelkirche in Mannheim an ${ }^{54}$ ). Dieses zur selben Zeit wie die Jakobskirche von dem kurpfälzischen Oberbaumeister Johann Peter Wachter erbaute Gotteshaus war, soweit das der Stich erkennen läßt, der Schöpfung Charraskys stilistisch in mancher Hinsicht verwandt. Die Elemente, welche an beiden Bauten wiederkehrten, waren: 1. der hohe umlaufende, mit Fuß- und Kopfgesims ausgestattete Sockel; 2. die Säulenädikula-Portale mit Dreieckgiebeln; 3. die niedrigen, direkt über dem Sockel ansetzenden Fenster mit Ohrengewänden; 4. die hohen, durch zwei Pfosten und Maßwerk (Rosettensegmente) unterteilten Fenster der oberen(Haupt-)Ordnung; 5. das kräftige, den Baukörper oben abschließende, vollständige Gebälk und 6. das niedrige, ungegliederte Zwischengeschoß des Turms. Außerdem begegnete an der Fassadenattika der Jakobskirche das gleiche Ornament - ein gekreuztes Palmwedelpaar - wieder, das den Mittelgiebel der Mannheimer Kirche schmückte. Die Kleeblattfenster im Fassadenobergeschoß der Jakobskirche schließlich hatten ihre genauen Entsprechungen über dem Turmhelmansatz des Wachterschen Baus.

So zahlreich und auffallend die Ubereinstimmungen waren: es bestanden dennoch erhebliche Unterschiede, die letztlich auf sehr verschiedene Künstlertemperamente zurückschließen lassen. Wachter gliederte seinen Bau vertikal durch schmale und breite Mauerlisenen, welche seltsamerweise Basen, aber keine Kapitelle oder Kopfgesimse hatten. Charrasky wählte breite Pilaster mit jonischen Kapitellen; nur für das Turmuntergeschoß Lisenen des Wachterschen Typs. Wachter verstand es, Mauerflächen zu vornehm-ruhiger Geltung zu bringen. Charrasky vermied, aus einem wahren horror vacui heraus, alle Flächigkeit so gut es ging; selbst den Fassadensockel überzog er noch mit Ornamentreliefs. Wachters Haltung läßt sich vorsichtig mit klassizistisch, die Charraskys mit manieristisch kennzeichnen. Man spürt eben, daß der Ungar im Grunde als Bildhauer empfand, daß es ihm auf eine konsequente Durchbildung aller Teile ankam.

Fragt man weiter, welche Schulung eine solche Haltung bedingt, welches Erlebnis sie gefördert haben könnte, so sieht man sich auf die Würzburger Architektur ver-

${ }^{54)}$ Vgl. Riedi, Heidelberger Jesuitenkirche, S. 89 f. und S. 232. Abbildung des Stichs bei Friedrich WaLter, wie unter Anm. 50 zitiert. 
wiesen, und zwar auf die des späten 16. und des frühen 17. Jahrhunderts. Man denkt vor allem an die südliche Langseite der Neubaukirche mit ihrer dichten Pilaster- und Maßwerkfenster-Gliederung. Eine Detailverwandtschaft der Neubau- und der Jakobskirche läßt noch besonders aufmerken: die Sockel beiderseits des Hauptportals des Würzburger Baus haben genau wie der Fassadensockel des Heidelberger geometrischen und vegetabilen Reliefschmuck. - Daß die Neubaukirche auf Charrasky Eindruck gemacht haben soll, braucht nicht zu verwundern: so große Architekten wie Petrini und Greissing haben sich vom reichen Formenschatz des Bauwerks aus der Juliuszeit anregen lassen.

Leider ist es mir nicht gelungen, ein mögliches Vorbild für das Fassadenobergeschoß der Jakobskirche zu finden; die sehr merkwürdigen viertelscheibenförmigen seitlichen Stützwände haben in Mainfranken und in der Kurpfalz jedenfalls kaum ihresgleichen.

Als Ergebnis unserer Betrachtung ist festzuhalten, daß Charrasky entscheidende Anregungen von Johann Peter Wachter und ganz sicher auch aus Mainfranken empfing. Eine genaue Stilanalyse der erhaltenen Skulpturen Charraskys (es scheint, als ob auch auf bildhauerischem Gebiet Zusammenhänge mit Würzburg bestünden) könnte das Geheimnis der künstlerischen Herkunft unseres Meisters weiter lüften.

\section{Die Ausstattung der Karmelitenkirche}

Die Ausstattung der Karmelitenkirche ist einer eingehenden Betrachtung wert; war es doch möglich, zahlreiche Inventarstücke wiederzuentdecken.

Man darf unterstellen, daß die Karmeliten bei der Ubernahme der ausgebrannten Kirche im Jahre 1701 keine oder doch sehr wenige Einrichtungsgegenstände vorfanden. Es blieb ihre Aufgabe, nach und nach Mobiliar und Schmuck anzuschaffen. Wie sehr die Mönche dabei auf mildtätige Stiftungen angewiesen waren, wird sich gleich zeigen. - Am sinnvollsten scheint es, der Besprechung der wiedergefundenen Stücke die Erläuterungen HerTwigs vorauszuschicken.

Im ersten Jahrzehnt des 18. Jahrhunderts erhielt die Klosterkirche bereits eine Orgel: „Die kurfürstliche Hofkammer besaß ein Positiv, oder eine kleine Orgel, welche sie von einem Kanzlisten übernommen hatte ... Die Väter bathen ..., daß sie der St. Jacobskirche zuerkannt werde... Dieß Positiv fanden noch jene, die fast nach 100 Jahren das Kloster ausräumten" " ${ }^{55}$ ).

Im Jahre 1719 „schenkte eine Frau Namens Hoggius das schöne Bild, welches Mitten vom St. Josephsaltar unter der Statue dieses Heiligen angebracht ist, und das Haupt unseres Heilandes vorstellt. Jeder Kenner hält es für ein Meisterstück der Malerkunst ${ }^{(56)}$ ). - 1722 stiftete die Frau Pfalzgräfin Elisabetha Augusta, die den "Ordensmännern besonders geneigt war, einen hohen Altar, wie ihn die Größe der Kirche forderte" ${ }^{57}$ ). „Den 7. Januar 1722 ward mit dem damaligen Hofschreiner Sigismund Zeller der Kontrakt geschlossen, worinn er versprach, für tausend Gulden den Altar, ohne Bildhauer-, ohne Mahlerarbeit und ohne Tabernakel in Zeit eines halben Jahrs aufzurichten. Er hielt sein Versprechen und empfing das bedungene Geld. Bildhauer und Mahler kosteten noch zwölfhundert Gulden." - 1728 folgte der Pfalzgraf dem Beispiel seiner Gemahlin und stiftete seinerseits einen Altar; der Prior schloß am 13. August auf Befehl des Herrschers „mit dem Schreinermeister Mathäus Nestler den
55) Hertwig, S. 34.
56) Hertwig, S. 58.
57) Hertwig, S. 64. 
Accort, einen St. Josephsaltar von Eichenholz in die Kirche zu setzen. Der Meister versprach alle Bildhauer- und Schnitzarbeit dabey zu übernehmen " ${ }^{58}$ ). - Um 1736, unter dem Priorat Pater Christians, wurden „die zwey kleinere Altäre, einer zu Ehren des h. Johann Vom Kreuze, der andere zu Ehren des h. Johann von Nepomuk im Chor errichtet“ ${ }^{59}$ ). „1753 trug H. Graf v. Wiser - eben jener, der in der Gruft der St. Jacobskirche für sich und seine Familie einen Begräbnißort errichten ließ - dem Prior fünfzig Gulden an Geld ... an, damit nächst der Kanzel ein neuer Muttergottesaltar errichtet werde, der in allem dem St. Josephsaltar glich. Zwei Statuen Joseph und Lucia sollten neben das Muttergottesbild gestellt, und ober dieser das gräfliche Wappen angebracht werden ... Im folgenden Jahre war der Altar fertig “ ${ }^{60}$ ). - Um 1753 wurden die beiden Altäre im Chor gefaßt, "wovon einer an der Thüre der Sakristei, der andere an der Thüre des Glockenturms stehet" ${ }^{61}$ ). - Zur selben Zeit bewarb sich „der damalige Prediger V. Wendelin ... um eine neue Kanzel für die Kirche ... Dieser (der Schreinermeister, Anm. d. V.) versprach eine neue Kanzel von Eichenholz und schnitzwerk zu liefern und aufzurichten" ${ }^{62}$ ). Der Auftrag wurde entsprechend ausgeführt. Jedoch blieb die Kanzel bis 1776 ungefaßt; zusammen mit dem Muttergottesaltar, der auch "noch im rauhen Holze" stand, wurde sie zu dieser Zeit vollendet ${ }^{63}$ ).

Nur noch einmal kommt Pater Her Twig auf die Ausstattung der Kirche zu sprechen, diesmal im Zusammenhang mit den traurigen Ereignissen des März 1809: „Die Kirche ward ausgeleert. Die Orgel durfte den Vätern in die Kapuzinerkirche folgen. Alles andere ward versteichert, und jenem überlassen, der auch nur etwas weniges dafür bot. So steicherte ein Zimmermann den sehr schön gefaßten hohen Altar, der die Breite und Höhe des Chors ausfüllte, für zwey und zwanzig Gulden, welchen ihm bald darnach die Gmeinde von Mühlhaussen im Brurhein für drey und dreysig Gulden wieder abnahm. Die beiden Nebenaltäre kaufte die Kirche zu Oestringen. Die Statuen der Heiligen, die die inneren Kirchenmauern zierten, kamen zum Theile nach Zeuthern: für jede ist ein Gulden bezahlt worden. Diese Gemeinde kaufte auch um weniges Geld die Kanzel und die Beichtstühle für ihre Kirche. Die ausgeleerte Kirche ward sammet dem Kloster eingerissen ..." - wir kennen die weitere Geschichte ${ }^{64}$ ).

Die Rekonstruktion der Ausstattung muß von den Beschreibungen Hertwigs und den erhaltenen Plänen ausgehen, das Forschen nach dem Verbleib der Stücke von der eben zitierten Schilderung.

Hochaltar. Der Hochaltar Sigismund Zellers ist, soviel ich ermitteln konnte, verschollen. Die Mühlhausener Pfarrkirche ${ }^{65}$ ) wurde im späten 19. Jahrhundert und kürzlich wieder umgebaut; irgendwelche Anhaltspunkte, daß der Hochaltar jemals in Mühlhausen gestanden hat, fehlen. Vielleicht beruht Hertwigs Angabe auch auf einem Irrtum. - Ein Verlust des Altars wäre höchst bedauerlich. Der Preis von 2200 Gulden läßt auf eine sehr prunkvolle und monumentale Retabelanlage schließen. Zweifellos würde die (immerhin mögliche) Wiederauffindung unser Bild von der Kunst des Hofschreiners und späteren Hofbaumeisters Sigismund Zeller beträchtlich erweitern.

Mit ziemlicher Sicherheit läßt sich von dem Altar sagen, daß er ein Jakobsaltar war. Festgelegt ist sein Standort, genauer: sind seine beiden Standorte im Chor der Karmelitenkirche. Bis 1736 befand er sich im Chorhaupt; im Anschluß an die von
58) HeRtwig, S. 96.
62) Hertwig, S. 167.
59) Hertwig, S. 109.
63) Hertwig, S. 243.
${ }^{60)}$ Hertwig, S. 165.
$\left.{ }^{65}\right)$ Es handelt sich um den Ort Mühlhausen bei Wiesloch.
61) Hertwig, S. 166. 
Zeller geleitete Erstellung der Fürstengruft wurde er dann weiter nach Westen versetzt. Die nunmehrige Situation ist auf dem Plan Abb. 3 markiert.

Nebenaltäre. Die beiden großen Nebenaltäre sind nicht nach Oestringen verkauft worden; in diesem Punkte ist HeRTwig falsch unterrichtet. Allerdings braucht das nicht weiter zu befremden: man muß bedenken, daß der greise Mönch den Schluß seiner Chronik in der turbulenten Zeit nach der Klosteraufhebung geschrieben hat. Gerade die aufregenden jüngsten Ereignisse, dazu noch ein so unübersichtliches Geschehen wie die Versteigerung des Klosterguts, werden ihm wohl in ihren Einzelheiten entgangen sein. - Im Verlauf einer systematischen Suche nach Heidelberger Kunstwerken fand ich den Marien- und den Josephsaltar in der katholischen Pfarrkirche zu Malsch bei Wiesloch. Die wenigen Hinweise bei Hertwig hätten allein schon eine sichere Identifizierung gestattet. $\mathrm{Zu}$ allem Überfluß ist im Pfarrarchiv eine $\mathrm{Ab}$ schrift aus dem "Hausbüchlein von einem Verwandten des Bürgermeisters Maier" folgenden Inhalts vorhanden:

"13. Marti 1809 haben wir Schuldeis Erhard Sebastian Rösch und Joseph Müller Schreiner Meister, die Nebenaltär gesteigt zu Heidelberg in der Karmelitenkirch den Josephsaltar vor $170 \mathrm{fl}$. den Mutter Gottesaltar vor 215. “ ${ }^{66}$ ) - Diese Beträge weichen sehr erheblich von den sonst (etwa für den Hochaltar) bezahlten Schleuderpreisen ab; möglicherweise haben sich die Abgeordneten der Gemeinde Oestringen aus der Angelegenheit ein Geschäft gemacht und die eben für wenig Geld ersteigerten Altäre an Ort und Stelle gleich den beiden Malschern teuer weiterverkautt. Eine solche Uberlegung würde den Widerspruch zwischen der Aussage Hertwigs und dem Tatbestand erklären.

Die beiden Altäre gleichen einander im Aufbau völlig; Graf Wiser hatte ja 1753 ausdrücklich verlangt, daß der zu erstellende Muttergottesaltar dem Josephsaltar nachgebildet werde. Über verkröpftem, konvexem Sockel erhebt sich zu beiden Seiten eines tief ausgenischten Mittelteils je ein versetztes Säulenpaar mit Pilasterrücklage; das üppig profilierte Hauptgebälk ist dem Querschnitt dieser Ordnung entsprechend bewegt verkröpft. Über den äußeren Gebälkverkröpfungen schwingen sich Schweifgiebelstücke mit eingerollten Enden empor; der obere Aufzug über der Gebälkmitte wird von gebogenen Pilastern mit abschließenden Volutenvorlagen flankiert und von einem wiederum reichprofilierten und -verkröpften Gesims mit seitlichen Schweifgiebelstücken und einer Akanthuskartusche in der Mitte bekrönt. Auf den Giebelstücken des Hauptgeschosses und auf denen des Aufzugs sitzt je eine Engelsfigur. Gleich behandelt sind an beiden Altären auch die Hauptgeschoßnischen (unter einem halbkugelförmigen Baldachin gibt ein rechts und links gerafter Vorhang den Blick auf die Titelfigur frei), desgleichen die Mittelfelder der oberen Aufzüge (Heiligenbild mit Wölkchenrahmen). Beiderseits der Hauptnischen zwischen den Säulen sind Konsolen angebracht; die zugehörigen Figuren fehlen. Die Altäre sind grau marmoriert, ihre Ornamentdekorationen teilweise vergoldet ${ }^{67}$ ).

Der Josephsaltar zeichnet sich einmal durch eine schöne, lebensgroße Gruppe "Joseph und das Christuskind" aus; weiter durch die darunter eingefügte (bereits 1719 dem Kloster gestiftete) Darstellung des Hauptes Christi. Ober der Nische prunkt noch das kurfürstliche Wappen; diesem entspricht am Marienaltar eine Rocaillekartusche, die ehedem sicher das gräflich Wisersche Wappen trug, heute aber die

$\left.{ }^{66}\right)$ Pfarrarchiv Malsch, Fasz. 9: Consecration der Altäre betr. Abschrift am 13.1.1905 vom Pfarramt Malsch beglaubigt.

${ }^{67}$ ) Die Fassung ist wohl neueren Datums. 
Buchstaben $A \Omega$ zeigt. Die Rocailleformen dieses Wappenschilds sind bemerkenswerterweise das einzige am ganzen Marienaltar, was an die Entstehungszeit (1753) erinnert. Die Marienfigur ist bestimmt schon vorhanden gewesen, als der Altar entstand. Ausdrücklich spricht HeRTwig ja von einem neuen Marienaltar, so daß das Vorhandensein eines alten vorausgesetzt werden darf; von ihm wurde wohl die Marienstatue übernommen. Meiner Úberzeugung nach hat sie derselbe vortreffliche Meister geschnitzt, dem wir die Josephsfigur verdanken (vgl. Gesichtstypen, Faltenstil). Darf man die Nachricht "Schreinermeister Mathäus Nestler“ (ein "Mathias Nestler“ ist als Fertiger der Kanzel in der Heiliggeistkirche, 1728, überliefert) habe versprochen, "alle Bildhauer- und Schnitzarbeit ... zu übernehmen" so auslegen, als ob Nestler selber Bildhauer gewesen sei? Oder will diese Nachricht vielmehr besagen, daß Nestler die Bildhauerarbeit weitervergeben hat, um lediglich den Tischleranteil auszuführen? - Im Falle der Richtigkeit der ersten Auslegung hätten wir in Nestler einen der bedeutenderen pfälzischen Bildhauer der ersten Hälfte des 18. Jahrhunderts vor uns. Eine eigene Arbeit hätte hier Klarheit zu schaffen. Immerhin ist der Rang Nestlers als Altargestalter jetzt schon offenkundig. Ich wüßte kein Retabel aus dem ersten Drittel des 18. Jahrhunderts in Heidelberg oder Heidelbergs näherer Umgebung zu nennen, das einen Vergleich mit den Malscher Altaraufbauten aushielte. Es wäre zu fragen, inwieweit Sigismund Zellers Hochaltar etwa für Nestler richtungsweisend war. - Die ehemaligen Standorte der beiden Seitenaltäre sind wiederum aus dem Plan Abb. 3 zu ersehen: sie waren vor den Wänden rechts und links des Choreingangs.

Die „zwey kleinern Altäre im Chor“", der St. Nepomuks- und der St. Johann vom Kreuz-Altar, sind nicht mehr nachzuweisen. Sie waren einst vor der Doppelstufe in der Chormitte schräg zum Hochaltar aufgestellt. Ich komme im anderen Zusammenhang auf diese beiden Altäre zurück.

Kanzeln. Die Kanzel in der Pfarrkirche zu Zeutern (bei Bruchsal) kann nicht um 1753 entstanden sein; ihre Formen weisen auf das erste, allenfalls noch das zweite Jahrzehnt des 18. Jahrhunderts. Es handelt sich um eine Rechtskanzel mit Hängekorb und Schalldeckel. Der ungleichseitig sechseckige Korb besteht aus einer umgedrehten, ganz flachen Schweifkuppel, einem an den Polygonecken verkröpften, ornamentierten Fußgesims, den Korbwandungen und einem abschließenden Gebälk; vor die Brechungen des Korbprimas sind Säulchen gestellt. Der stark ausladende Schalldeckel ist, dem Grundriß des Korbes entsprechend, von schwerem Gebälk umzogen; über den Eckverkröpfungen ranken sich insgesamt fünf Akanthusvoluten empor; sie begegnen einander über der Mitte des Deckels und bilden gemeinsam die Stütze für das Nest eines sich opfernden Pelikans. Durchbrochene diademartige Akanthusornamente zwischen den Volutenansätzen vervollständigen die Bekrönung des Schalldaches. - Das Fußgesims und die Brüstungsfüllungen des Korbes und der Gebälkfries des Deckels sind mit Akanthusrankenwerk ausgeziert; die Kanzel ist grau marmoriert; alle Ornamente sind vergoldet. - Das Ganze macht einen reichen und gediegenen Eindruck.

Warum bespreche ich diese Kanzel? HERTWIG berichtet doch von einer Kanzel, die um 1753 angefertigt wurde; und auf dem Plan im Kurpfälzischen Museum ist unweit des linken Seitenaltars eine Kanzel mit bewegtem, aus Schweiflinien zusammengesetztem Grundriß erkennbar. Kann die Zeuterner Kanzel demnach überhaupt aus der Karmelitenkirche stammen? Wie wir sehen werden, sind noch andere Ausstattungsstücke der Karmelitenkirche nach Zeutern gelangt; ich möchte daher, was die Kanzel betriff, Hertwigs Aussage für richtig halten. Es müßte sich folglich um die 
erste Kanzel der Karmelitenkirche handeln, also um die Vorgängerin der um 1753 gefertigten. HERTwig spricht ja ausdrücklich von der Anschaffung einer "neuen“ Kanzel; mithin wird eine ältere vorhanden gewesen sein. Ob nur ästhetische oder auch praktische Gründe für die Ersetzung des alten Stücks durch ein neues maßgeblich waren, läßt sich nicht ausmachen; etwas verwunderlich ist, daß man die abgebrochene Kanzel (offenbar sehr sorgfältig) magazinierte.

Was aber ist mit der neueren Kanzel geschehen? Ich glaube, die Antwort geben zu können. In der Pfarrkirche zu St. Leon bei Wiesloch befindet sich eine hervorragend schöne Rokokokanzel, deren Korbgrundriß dem auf genanntem Plan festgehaltenen Grundriß entspricht; es handelt sich zudem um eine Linkskanzel. Der Kanzelkorb ist ziemlich breit, hat einen blütenkelchartigen Bodenteil, eine elegant geschweifte Frontwand, eine schmälere, gleichfalls geschwungene Seitenwand und überreichen Volutenund Rocaillebesatz; in einer großen Rocaillekartusche der Frontwand ist das Monogramm CT (Carl Theodor) zu lesen. Der Kanzelkorb ist über eine steile, gerade geführte Treppe mit kassettierter und ornamentierter Brüstung erreichbar. Zwischen Kanzelkorb und Schalldeckel vermittelt eine schwungvoll konturierte Dorsalplatte. Der Schalldeckel hat eine pagodendachähnliche Form, üppigen Rocaillezierat und eine Bekrönungsfigur (Paulus mit gezücktem Schwert). Alle Wandungen der Kanzel sind naturholzlasiert, alle Ornamente vergoldet.

Uber den hohen künstlerischen Rang der Kanzel gibt es keinen Zweifel; die temperamentvolle, wirkungssichere Durchgestaltung - im großen wie im kleinen - nötigt einem Bewunderung ab. Im Umkreis Heidelbergs gibt es keine Rokokokanzel, welche einen Vergleich mit der St. Leoner aushielte. Leider fehlt jeder Hinweis auf den Meister. Daß die Kanzel wirklich aus der Karmelitenkirche stammt, wird durch eine weiter unten erläuterte Tatsache erhärtet.

Beichtstüble. Der Grundriß im Kurpfälzischen Museum läßt sechs Beichtstühle erkennen; in Zeutern fand ich nur zwei. Diese Beichtstühle haben den üblichen Trapezgrundriß; ihr tektonisches Gerüst setzt sich aus vier Säulen mit Pilasterrücklagen (ein Säulenpaar flankiert das Priestergehäuse, ein zweites begrenzt den Beichtstuhl seitlich) und darüberliegendem, zurückhaltend verkröpftem Gebälk zusammen. Ein Gemälde, seitlich durch Holztafeln mit volutenförmigem Umriß gestützt und bekrönt von einer Vase (spätere Zutat?), bildet jeweils eine Art oberen Aufzug; die Zwickel über der rundbogigen Óffnung des Priestergehäuses sind mit beflügelten Engelsköpfchen verziert, jene über den Öffnungen der Beichtnischen sowie der Gebälkfries mit Akanthusranken ausgesetzt. Die erwähnten Gemälde haben auf Schuld und Sünde bezügliche Themen zum Gegenstand; auf dem einen ist die büßende Magdalena, auf dem anderen Petrus als Verleumder dargestellt. - Die Beichtstühle sind vorzüglich gearbeitet; das Holz ist gefirnist, so daß seine Maserung sehr schön zur Geltung kommt. - Stilistische Eigentümlichkeiten (Ornamentbehandlung) erlauben eine $\mathrm{Da}$ tierung um 1715-1720. Manche Details (Akanthusranken!) stimmen mit solchen der Zeuterner Kanzel überein.

Heiligenfiguren. Die Kirche in Zeutern beherbergt sieben farbig gefaßte, in der Qualität unterschiedliche, ohne jede Frage zu ein und derselben Reihe gehörende lebensgroße Schnitzfiguren (auf Wandkonsolen). Die geläufige Behauptung, diese Figuren stammten aus Heidelberg, wird durch die Aufzeichnung HerTwigs bestätigt ${ }^{69}$ ). (Andererseits ist das Vorhandensein der Statuen in Zeutern eine Gewähr für die

\footnotetext{
${ }^{68)}$ Dehio-GalL: Handb. d. Deutschen Kunstdenkmäler, Rheinfranken. Berlin 1943. S. 417.
} 
Verbindlichkeit der HeRrwigschen Feststellung, auch Kanzel und Beichtstühle seien nach Zeutern verkauft worden.)

Besonders schön und beachtenswert sind zwei Figurenpaare: Joseph mit dem Christuskind und Anna mit der kindlichen Maria (Kopf der Maria im 19. Jahrhundert ergänzt?). Offenbar stammen diese Werke von derselben Hand wie die beiden Malscher Altargruppen, also vielleicht von der Hand des Matthäus Nestler. Freilich unterscheiden sich die Statuen erheblich: die in Zeutern sind weich, labil, die Falten ihrer Gewänder wulstig, ungeordnet; die in Malsch dagegen sind straff (ohne deshalb steif zu sein), ihre Gewandfalten schnittig begrenzt, bestimmten Bewegungszügen untergeordnet. Trotzdem überwiegen die Gemeinsamkeiten die Andersartigkeiten: hauptsächlich Gesichter und Hände verraten denselben Urheber. Ich möchte annehmen, daß die Zeuterner Figuren früher entstanden sind als die Malscher (etwa um 1720); die Malscher (etwa um 1730) bekunden deutlich, daß der Meister inzwischen mit der Kunst Paul Egells in Berührung gekommen ist. - Eine Einzelbesprechung der anderen fünf Heiligenfiguren in Zeutern kann hier nicht erfolgen; ich möchte nur die Namen der Dargestellten nennen; St. Franziskus, St. Judas Thaddaeus, St. Karl Borromaeus, St. Helena und David. Die beiden erst- und die beiden letztgenannten scheinen jeweils stilistisch zusammenzugehören.

Hertwig spricht davon, daß nur ein Teil der Figuren nach Zeutern gelangt ist; die Frage, was denn mit den anderen Figuren geschehen ist, läßt sich vielleicht beantworten. In der Pfarrkirche zu St. Leon befinden sich vier Figuren der Heiligen Apolonia, Katharina, Walburga und Blasius, die zweifellos dem großen Statuenzyklus in der Karmelitenkirche angehört haben. Die St. Leoner Kirche birgt dazu noch (außer vier ihrerseits stilistisch miteinander verwandten Standbildern der Heiligen Leo, Hubertus, Valentin und Wolfgang - mit der Karmelitenkirche dürften diese Figuren nichts zu tun haben -) zwei hervorragende, von ein und derselben Kürstlerhand geschaffene, etwas unterlebensgroße Standbilder der Heiligen Nepomuk und Johannes vom Kreuz. Insbesonders die schlanke Nepomukfigur ist ungewöhnlich gewandt geschnitzt und sehr ausdrucksvoll. Der Meister wird im engeren Umkreis Egells zu suchen sein. In den beiden Statuen sind wohl die Titelfiguren der kleinen, um 1736 im Chor der Karmelitenkirche errichteten Altäre zu sehen. Die Kombination St. Nepomuk - St. Johannes vom Kreuz ist an sich nicht eben üblich; der Umstand, daß in St. Leon auch noch andere Inventarstücke aus der Karmelitenkirche vorhanden sind, dürfte die These erhärten ${ }^{69}$ ).

Auf die Frage nach den ehemaligen Anbringungsorten der elf großen Heiligenfiguren läßt sich keine genaue, auf die nach der Anordnungfolge überhaupt keine Antwort geben. Nach Hertwig zierten die Statuen die „inneren Mauern“ der Karmelitenkirche; wahrscheinlich waren sie, einzeln oder paarweise, an den Wänden zwischen den unteren Langhausfenstern angebracht.

Orgel. Die kleine, im ersten Jahrzehnt des 18. Jahrhunderts gestiftete Orgel war, nach Hertwig zu schließen, auf der Empore, dem „Odeum“, aufgestellt. 1809 durfte sie "den Vätern in die Kapuzinerkirche folgen“. Ich vermute, daß sie von da aus in den Heiliggeistchor übertragen wurde ${ }^{70}$ ). Uber ihr weiteres Schicksal kann ich keinen Aufschluß geben.

$\left.{ }^{69}\right)$ Andererseits wird dadurch auch wahrscheinlicher, daß die St. Leoner Kanzel aus der Karmelitenkirche stammt.

${ }^{70}$ ) Vgl. RiEDL, Heidelberger Jesuitenkirche, S. 62/63. 